\title{
ANALYSES OF PHASE STABILITY IN Nb-Cr-Si ALLOYS
}

\author{
B.P. Bewlay, K. Dovidenko, D. Ellis, A. Deal and J. Cournoyer \\ General Electric Global Research Center, Schenectady, New York 12301
}

Novel composites based on niobium solid solutions and niobium silicides, such as $\mathrm{Nb}_{5} \mathrm{Si}_{3}$ (tI32 crystal structure) and $\mathrm{Nb}_{3} \mathrm{Si}$ (tP32 crystal structure), are presently being developed for very hightemperature structural applications $[1,2]$. The use of alloying additions of elements such as $\mathrm{Cr}$ improves oxidation and environmental properties. The present paper describes the effect of $\mathrm{Cr}$ alloying additions on phase equilibria and microstructure of $\mathrm{Nb}-\mathrm{Si}$ alloys. Microstructural and electron backscatter diffraction (EBSD) analyses will be discussed.

$\mathrm{Nb}$-silicide in-situ composites typically form a niobium solid solution and a $\mathrm{Nb}$-silicide phase on solidification $[1,2]$. The alloys were prepared by directional solidification and heat treatment, as described previously [1]. A range of $\mathrm{Nb}-\mathrm{Cr}-\mathrm{Si}$ alloys was examined in order to define the liquidsolid and solid-solid phase equilibria. The alloys were analyzed in the as-cast and the heat treated conditions.

The microstructure of the cast $\mathrm{Nb}-8 \mathrm{Cr}-16 \mathrm{Si}$ alloy is shown in Figures 1(a) and (b). Figure 1(a) shows $(\mathrm{Nb})$ dendrites (light phase) and $(\mathrm{Nb})_{5} \mathrm{Si}_{3}$ (grey phase), with a fine-scale interdendritic ternary eutectic of $(\mathrm{Nb}),(\mathrm{Nb})_{5} \mathrm{Si}_{3}$, and $\mathrm{Cr}_{2} \mathrm{Nb}$ (black phase). The eutectic phases can be seen in some more detail at higher magnification in Figure 1(b). The solidification sequence of the phases in this alloy are similar to those predicted by thermodynamic modeling [3].

The microstructure of the cast $\mathrm{Nb}-25 \mathrm{Cr}-12 \mathrm{Si}$ alloy is shown in Figures 2(a) and (b). Figure 2(a) shows large-scale $(\sim 75 \mu \mathrm{m}) \quad(\mathrm{Nb})_{5} \mathrm{Si}_{3}$ dendrites (light grey phase), large-scale $(\mathrm{Nb})$ dendrites (light phase), and an interdendritic $(\mathrm{Nb})-(\mathrm{Nb})_{5} \mathrm{Si}_{3}-\mathrm{Cr}_{2} \mathrm{Nb}$ ternary eutectic. This alloy is from the Si-rich side of the $(\mathrm{Nb})-(\mathrm{Nb})_{5} \mathrm{Si}_{3}$ eutectic valley. The eutectic phases can be seen in more detail at higher magnification in Figure $2(\mathrm{~b})$; the $(\mathrm{Nb})_{5} \mathrm{Si}_{3}$ is the largest volume fraction. The combination of the volume fractions of $(\mathrm{Nb})$ and $\mathrm{Cr}_{2} \mathrm{Nb}$ in the eutectic is similar to that of the eutectic $(\mathrm{Nb})_{5} \mathrm{Si}_{3}$.

\section{References}

1. B.P. Bewlay, M.R. Jackson, and P.R. Subramanian, JOM, Vol 51(4) (1999), pp. 32-36.

2. M.G. Mendiratta and D.M. Dimiduk, Metall. Trans. Vol24A (1993), pp. 501-504.

3. B.P. Bewlay, Y.Yang, and Y.A Chang, submitted to Journal of Alloys and Compounds, February 2006. 

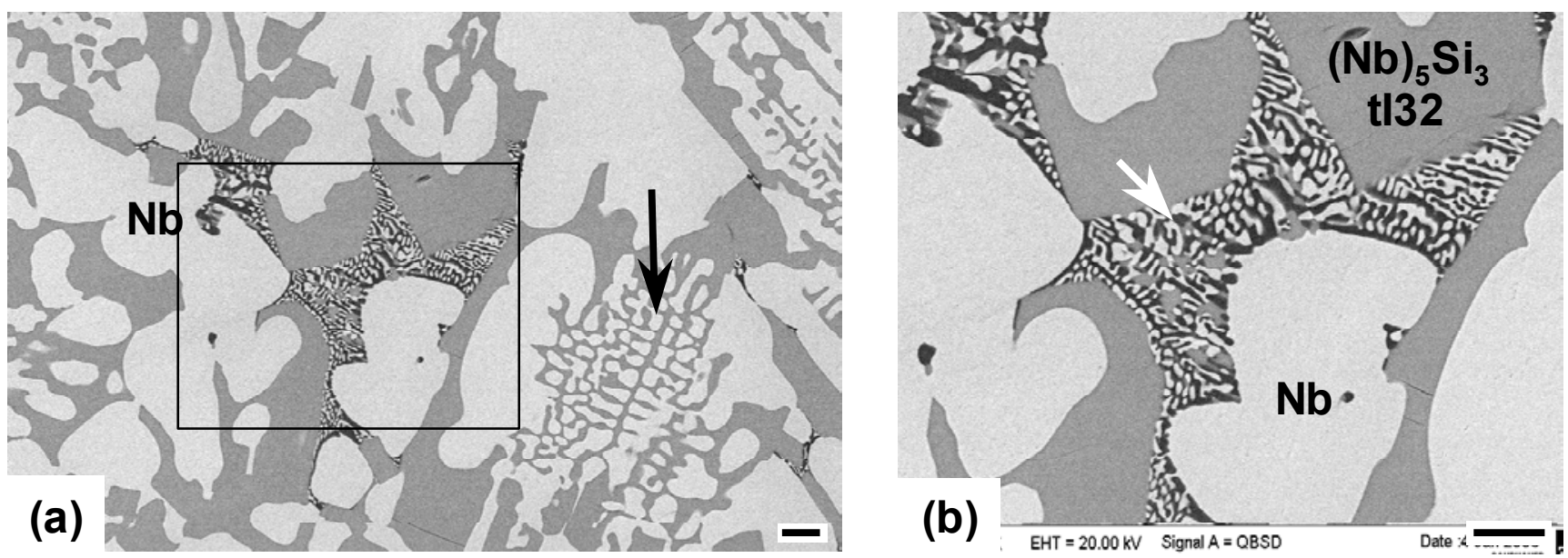

Fig. 1 Backscatter electron images of the Nb-8Cr-16Si alloy at (a) low, and (b) high magnifications. The black arrow indicates the $(\mathrm{Nb})-\mathrm{Nb}_{5} \mathrm{Si}_{3}$ eutectic region. The boxed area is magnified in (b)with the ternary eutectic region indicated by the white arrow. The scale bars are $10 \mu \mathrm{m}$.
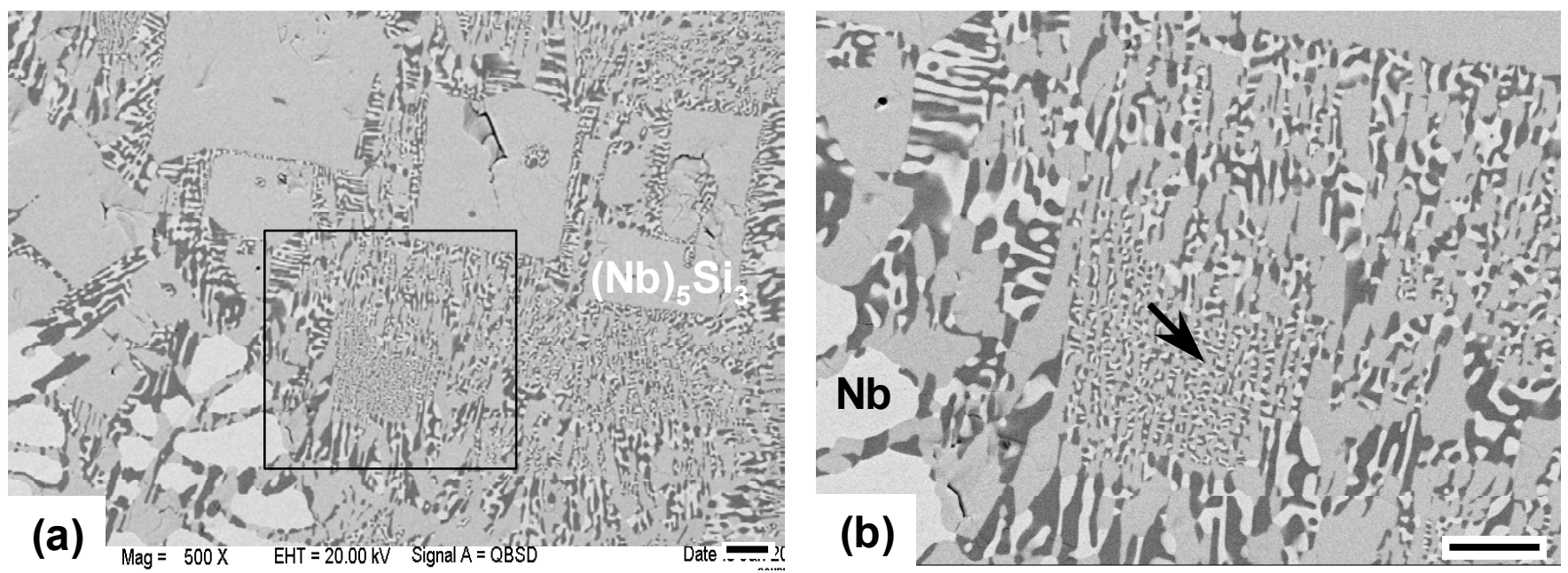

Fig. 2 Backscatter electron images of the Nb-25Cr-12Si alloy at (a) low, and (b) high magnifications. The boxed area in (a) is magnified in (b); the ternary eutectic region is indicated by the black arrow in (b). The scale bars are $10 \mu \mathrm{m}$. 